\title{
Effect of dendritic cell immunotherapy on distribution of dendritic cell subsets in non-small cell lung cancer
}

\author{
ZHONGFEI YANG $^{1 *}$, FANG DENG ${ }^{2 *}$ and LINGJUN MENG ${ }^{2}$ \\ Departments of ${ }^{1}$ Pneumology and ${ }^{2}$ Oncology, Dezhou People's Hospital, Dezhou, Shandong 253000, P.R. China
}

Received August 10, 2017; Accepted January 10, 2018

DOI: $10.3892 /$ etm.2018.6010

\begin{abstract}
The effect of dendritic cell (DC) immunotherapy on non-small cell lung cancer (NSCLC) and its influence on the distribution of DC subsets were studied. Peripheral blood was drawn from 55 patients, and DCs were cultured in vitro and injected into the patients three times. The changes in DC subsets in NSCLC patients before treatment and after three treatments were observed using a flow cytometer, and the difference in DC subsets between patients and healthy controls was compared. DC subsets in lung cancer tissues, para-carcinoma tissues and normal tissues were analyzed by indirect immunofluorescence and laser scanning confocal microscope (LSCM). The BDCA $-1^{+} \mathrm{DC} 1$ and $\mathrm{BDCA}-3^{+} \mathrm{DC} 2$ in lung cancer tissues were significantly increased compared with those in para-carcinoma tissues and normal tissues $(\mathrm{P}<0.05)$. The number of DC1 and DC2 in para-carcinoma tissues were increased compared with those in normal tissues $(\mathrm{P}<0.05)$. The ratio of $\mathrm{DC} 1$ in peripheral blood in the normal control group was obviously higher than that in NSCLC patients $(\mathrm{P}<0.01)$. There were significant differences in $\mathrm{DC} 1$ and $\mathrm{DC} 1 / \mathrm{DC} 2$ ratio in NSCLC patients with different tumor staging, and there were also obvious differences in patients with a different Karnofsky performance status (KPS) score. Moreover, compared with those before treatment, DC1 and DC1/DC2 ratio were significantly increased after three treatments, and there was a significant difference in the comparison of DC1/DC2 ratio between the NSCLC patients with survival time greater than and less than one year. The immune function of NSCLC patients was improved after DC immunotherapy. The survival time of NSCLC patients was closely associated with the $\mathrm{DC} 1 / \mathrm{DC} 2$ ratio in peripheral blood. The detection of DC subsets in peripheral blood can
\end{abstract}

Correspondence to: Dr Lingjun Meng, Department of Oncology, Dezhou People's Hospital, 1751 Xinhu Street, Dezhou, Shandong 253000, P.R. China

E-mail: dzhyy333@163.com

*Contributed equally

Key words: dendritic cells, immunotherapy, non-small cell lung cancer, dendritic cell subsets help clinicians understand the immune function of NSCLC patients and provide a basis for the clinical judgment of prognosis of NSCLC patients.

\section{Introduction}

Lung cancer is a malignant tumor with high morbidity and mortality rates that causes serious harm to patients and their families. With the increasing deterioration of the environment, the morbidity and mortality rates of lung cancer have shown a gradual upward trend $(1,2)$. Some scholars suggested that the immune function of patients becomes abnormal in the occurrence and development of lung cancer (3).

The dendritic cell (DC) is the most powerful antigenpresenting cell (APC) in the body, and plays a key role in immunological stress and immunoregulation of the body $(4,5)$. $\mathrm{DC}$ is a useful cell in tumor biological immunotherapy. Most scholars in China and worldwide hope to enhance the effect of immunotherapy by basis for the clinical judgment of prognosis improving the immune function and number of autologous DCs in patients, but the in vivo effect of DC immunotherapy is currently still significantly inferior to the in vitro effect. It has been confirmed that the number of DCs in the tumor-bearing host is reduced and it is defective with regard to its function compared with normal DCs $(6,7)$. This result is universally recognized as one of the important mechanisms of tumors evading immune surveillance in the body. Studies have shown that the changes in $\mathrm{DC} 1, \mathrm{DC} 2$ and $\mathrm{DC} 1 / \mathrm{DC} 2$ ratio in peripheral blood can well reflect the current immune function status of the body (8-10).

Therefore, the distribution and number of DC subsets in peripheral blood in patients with non-small cell lung cancer (NSCLC) after DC immunotherapy were detected in the present study to investigate the clinical significance of DC subset detection.

\section{Subjects and methods}

Subjects. A total of 55 patients, aged 19-77 years, who were diagnosed as NSCLC from January, 2016 to January, 2017 were selected. Exclusion criteria for the study were: Patients with dysfunction in heart, liver, kidney or hematopoietic function; child patients, pregnant women or mentally-ill patients; and patients without clear pathological diagnosis, or whose estimated survival was less than six months. Eighteen healthy 
subjects, aged 22-75 years, underwent physical examination and were selected as normal controls.

All the subjects signed informed consent, and this study was approved by the Dezhou Hospital Ethics Committee (Dezhou, China).

Reagents and instruments. The reagents and instruments used in the study were: BD dendritic cell flow cytometry reagent (Guangzhou Shuoheng Biotechnology Co., Ltd., Guangzhou, China); mouse mAb-BDCA-1 and mouse mAb-BDCA-3 (Shanghai Runwelltac Industrial Co., Ltd., Shanghai, China) and the corresponding secondary antibody and TO-PRO-3 (Shanghai Jiwei Biotechnology Co., Ltd., Shanghai, China); FACSCalibur flow cytometer (BD Biosciences, San Jose, CA, USA); laser scanning confocal microscope (LSCM) (Bio-Rad, Hercules, CA, USA) and small desktop high-speed centrifuge (BD Biosciences).

Detection using flow cytometer. In strict accordance with the instructions of BDDC flow cytometry reagent, DC flow cytometry reagent was added into the five heparin anticoagulant tubes, each containing $100 \mu 1$ peripheral blood, and the mixture was shaken gently and evenly, followed by reaction at room temperature in the dark for $15 \mathrm{~min}$. Then, 2-3 $\mathrm{ml}$ hemolysin was added and the mixture was shaken gently and evenly for splitting for $10 \mathrm{~min}$, followed by centrifugation at $1,080 \mathrm{x} \mathrm{g}$ for $5 \mathrm{~min}$. The supernatant was discarded, and the mixture was washed with phosphate-buffered saline (PBS) three times, added with $300 \mu \mathrm{l}$ PBS and gently agitated in the dark at $4^{\circ} \mathrm{C}$. The DC subsets were detected using the FACSCalibur flow cytometer. Cells $\left(5 \times 10^{4}\right)$ were collected into tubes. The threshold value was set in FSC to eliminate the interference of debris on the results. CellQuest software was used to obtain and analyze the HLA-DR positive, Lin-1 weakly positive and negative cell groups in the HLA-DR/Lin-1 point diagram. The results were recorded using the percentage of positive cells in CD11c (DC1) and CD123 (DC2) fluorescent antibody staining, while the $\mathrm{DC} 1 / \mathrm{DC} 2$ ratio was calculated.

Detection of the number of DC subsets in lung cancer, para-carcinoma and normal lung tissues. The lung cancer, para-carcinoma ( $2 \mathrm{~cm}$ around the cancer) and normal lung tissues were snap frozen and stored in liquid nitrogen $\left(-196^{\circ} \mathrm{C}\right)$. The above three kinds of tissues stored in the liquid nitrogen were taken, washed with the pre-cooled PBS and placed in the blocking solution containing $10 \%$ goat serum for $45 \mathrm{~min}$. Then, the tissues were placed in the diluent with donkey anti-goat BDCA-1 and BDCA-3 polyclonal antibodies (dilution, 1:20; cat. nos. AF5910 and AF3894; ) for incubation at $4^{\circ} \mathrm{C}$ overnight. Tissues were washed with pre-cooled PBS and goat anti-mouse secondary polyclonal antibody (dilution, 1:400; cat. no. AF109) was used for incubation at room temperature for $2 \mathrm{~h}$, followed by re-staining via TO-PRO-3 and sealing.

LSCM detection. LSCM was equipped with three kinds of ion lasers, namely argon-krypton (480 nm), chlorine-neon $(543 \mathrm{~nm})$ and helium-neon $(633 \mathrm{~nm})$. Using the objective and water lens (x20), confocal images were taken on the z-axis of the slide at an interval of $500 \mathrm{~nm}$, and the visual field with the most DCs was the field observed. The number of DC1- and DC2-positive cells were observed and counted by
Table I. Comparisons of DC subsets in peripheral blood between NSCLC patients and normal controls (mean \pm SD).

\begin{tabular}{lcccc}
\hline Groups & No. & DC1 & DC2 & DC1/DC2 \\
\hline NSCLC & 55 & $0.61 \pm 0.33^{\mathrm{a}}$ & $0.28 \pm 0.13$ & $3.15 \pm 2.97$ \\
Control & 18 & $0.79 \pm 0.24$ & $0.26 \pm 0.11$ & $3.94 \pm 1.89$ \\
t-value & & 2.884 & 0.537 & -1.526 \\
P-value & & 0.008 & 0.745 & 0.183 \\
\hline
\end{tabular}

${ }^{\mathrm{a}} \mathrm{P}<0.01$ compared with normal control group. DC, dendritic cell.

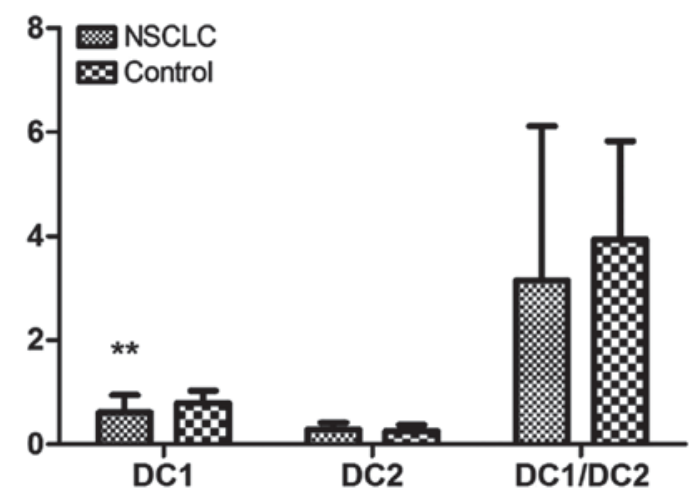

Figure 1. Dendritic cell (DC) subsets in peripheral blood in non-small cell lung cancer (NSCLC) patients and normal controls. ${ }^{* *} \mathrm{P}<0.01$, compared with control group.

two individuals, and the average count was taken; the count difference between the two individuals was not $>20 \%$.

Statistical analysis. SPSS 17.0 software (SPSS, Inc., Chicago, IL, USA) was used. Measurement data are presented as mean \pm SD. The ANOVA was used for the intergroup comparison and LSD test was used as post hoc test. The Chi-square test was used for the comparisons of enumeration data or rate; $\alpha=0.05$.

\section{Results}

Comparisons of DC subsets in peripheral blood between NSCLC patients and normal controls. The expression of DC1 in peripheral blood in NSCLC patients was significantly decreased compared with that in the normal control group, and the difference was statistically significant $(\mathrm{P}<0.01)$. The expression of DC2 did not change significantly in the NSCLC and normal control groups. Compared with that in the normal control group, the DC1/DC2 ratio in the NSCLC group was lower, but there was no statistically significant difference between the groups ( $\mathrm{P}>0.05)$ (Table I and Fig. 1).

Relationship between DC subsets and clinical features in NSCLC group. There were no statistically significant differences in the sex, age, pathological type, CEA and other DC subsets for the 55 NSCLC patients $(\mathrm{P}>0.05)$. There were statistically significant differences in $\mathrm{DC} 1$ and $\mathrm{DC1} / \mathrm{DC} 2$ ratio in NSCLC patients with different tumor staging $(\mathrm{P}=0.029$ 
Table II. Relationship between DC subsets and clinical features in NSCLC group.

\begin{tabular}{|c|c|c|c|c|c|c|c|}
\hline Characteristics & No. & $\mathrm{DC} 1$ & P-value & DC2 & P-value & $\mathrm{DC} 1 / \mathrm{DC} 2$ & P-value \\
\hline \multicolumn{8}{|l|}{ Sex } \\
\hline Male & 34 & $0.58 \pm 0.33$ & \multirow[t]{2}{*}{0.336} & $0.24 \pm 0.18$ & \multirow[t]{2}{*}{0.295} & $2.96 \pm 2.05$ & \multirow[t]{2}{*}{0.903} \\
\hline Female & 21 & $0.51 \pm 0.24$ & & $0.21 \pm 0.13$ & & $2.79 \pm 1.88$ & \\
\hline \multicolumn{8}{|l|}{ Age (years) } \\
\hline$<70$ & 40 & $0.62 \pm 0.34$ & \multirow[t]{2}{*}{0.103} & $0.25 \pm 0.13$ & \multirow[t]{2}{*}{0.135} & $2.67 \pm 1.75$ & \multirow[t]{2}{*}{0.194} \\
\hline$\geq 70$ & 15 & $0.48 \pm 0.29$ & & $0.21 \pm 0.15$ & & $3.86 \pm 3.27$ & \\
\hline \multicolumn{8}{|l|}{ Staging } \\
\hline Early & 18 & $0.77 \pm 0.28$ & \multirow[t]{2}{*}{$0.029^{\mathrm{a}}$} & $0.26 \pm 0.15$ & \multirow[t]{2}{*}{0.894} & $4.47 \pm 3.01$ & \multirow[t]{2}{*}{$0.001^{\mathrm{b}}$} \\
\hline Late & 37 & $0.52 \pm 0.23$ & & $0.25 \pm 0.13$ & & $2.56 \pm 1.73$ & \\
\hline \multicolumn{8}{|l|}{ Pathology } \\
\hline Adenocarcinoma & 36 & $0.59 \pm 0.32$ & \multirow[t]{3}{*}{0.406} & $0.27 \pm 0.12$ & \multirow[t]{3}{*}{0.184} & $2.89 \pm 2.15$ & \multirow[t]{3}{*}{0.243} \\
\hline Squamous carcinoma & 15 & $0.63 \pm 0.36$ & & $0.31 \pm 0.19$ & & $2.46 \pm 1.63$ & \\
\hline Others & 4 & $0.74 \pm 0.44$ & & $0.24 \pm 0.15$ & & $4.41 \pm 2.74$ & \\
\hline \multicolumn{8}{|l|}{ KPS } \\
\hline$<60$ & 20 & $0.48 \pm 0.31$ & \multirow[t]{2}{*}{$0.025^{\mathrm{a}}$} & $0.26 \pm 0.12$ & \multirow[t]{2}{*}{0.184} & $2.62 \pm 1.84$ & \multirow[t]{2}{*}{0.402} \\
\hline$\geq 60$ & 35 & $0.72 \pm 0.38$ & & $0.29 \pm 0.18$ & & $3.14 \pm 3.08$ & \\
\hline \multicolumn{8}{|l|}{ CEA } \\
\hline Normal & 26 & $0.68 \pm 0.41$ & \multirow[t]{2}{*}{0.091} & $0.29 \pm 0.18$ & \multirow[t]{2}{*}{0.724} & $3.62 \pm 2.96$ & \multirow[t]{2}{*}{0.056} \\
\hline Abnormal & 29 & $0.57 \pm 0.38$ & & $0.26 \pm 0.13$ & & $2.38 \pm 1.44$ & \\
\hline
\end{tabular}

${ }^{\mathrm{a}} \mathrm{P}<0.05$ and ${ }^{\mathrm{b}} \mathrm{P}<0.01$. NSCLC, non-small cell lung cancer; KPS, Karnofsky performance status; DC, dendritic cell.

Table III. Comparisons of DC subsets in peripheral blood before and after three DC treatments.

\begin{tabular}{lcccc}
\hline Groups & No. & DC1 & DC2 & DC1/DC2 \\
\hline Control & 18 & $0.79 \pm 0.24$ & $0.26 \pm 0.11$ & $3.94 \pm 1.89$ \\
Before treatment & 55 & $0.61 \pm 0.33$ & $0.28 \pm 0.13$ & $3.15 \pm 2.97$ \\
After treatment & 55 & $0.72 \pm 0.26^{\mathrm{a}}$ & $0.27 \pm 0.12$ & $3.54 \pm 2.38^{\mathrm{b}}$ \\
\hline
\end{tabular}

${ }^{a} \mathrm{P}<0.01$ and ${ }^{b} \mathrm{P}<0.05$, compared with that before treatment. DC, dendritic cell.

and $\mathrm{P}=0.001$ ), while there were statistically significant differences in patients with a different Karnofsky performance status (KPS) scores $(\mathrm{P}=0.025)$ (Table II).

Comparisons of DC subsets in peripheral blood before and after three DC treatments. In NSCLC, DC1 expression was low, and the immune function of body was decreased significantly. The DC1 content and DC1/DC2 ratio after three DC treatments were significantly increased compared with those before treatment (Table III).

Relationship between peripheral blood subsets and prognosis of NSCLC patients. After three DC treatments, 49 NSCLC patients were followed up for $>1$ year and 32 patients were lost to follow-up or died, and the 1-year survival rate was $34.7 \%$. There were no statistically significant differences in the comparisons of DC1 and DC2, limited
Table IV. Relationship between peripheral blood subsets and prognosis of NSCLC patients.

\begin{tabular}{llcrr}
\hline & \multicolumn{2}{c}{ Survival time } & & \\
\cline { 2 - 3 } Groups & $\geq 1$ year & $<1$ year & t-value & P-value \\
\hline DC subset & & & & \\
DC1 & $0.71 \pm 0.33$ & $0.65 \pm 0.36$ & -1.488 & 0.122 \\
DC2 & $0.29 \pm 0.17$ & $0.27 \pm 0.15$ & -0.174 & 0.916 \\
DC1/DC2 & $2.94 \pm 1.24$ & $1.73 \pm 1.27$ & -2.546 & 0.019
\end{tabular}

NSCLC, non-small cell lung cancer; DC, dendritic cell.

by 1 -year survival time $(\mathrm{P}=0.122$ and $\mathrm{P}=0.916)$, but there was statistically significant difference in the $\mathrm{DC} 1 / \mathrm{DC} 2$ ratio between patients with the survival time of greater than and less than one year $(\mathrm{P}=0.019)$ (Table IV).

The number of DC subsets in lung cancer, para-carcinoma and normal lung tissues. The number of DC1 in para-carcinoma and normal lung tissues was significantly lower than that in lung cancer tissues, and the difference was statistically significant $(\mathrm{P}<0.05)$. The number of $\mathrm{DC} 2$ in para-carcinoma and normal lung tissues was also evidently lower than that in lung cancer tissues, and the difference was statistically significant $(\mathrm{P}<0.05)$. Compared with those in normal lung tissues, the number of DC1 and DC2 in para-carcinoma tissues was increased significantly, and the differences were statistically significant $(\mathrm{P}<0.05)$ (Fig. 2). 


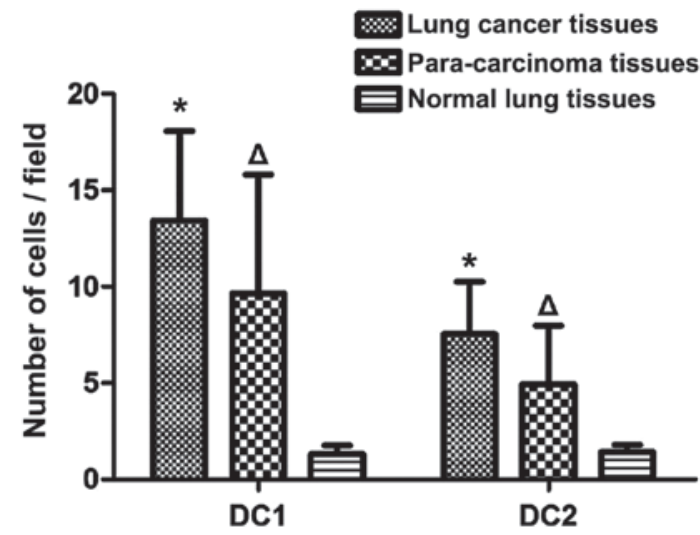

Figure 2. The number of dendritic cell (DC) subsets in lung cancer, para-carcinoma and normal lung tissues. ${ }^{*} \mathrm{P}<0.05$ compared with that in para-carcinoma and normal tissues; ${ }^{\wedge} \mathrm{P}<0.05$ compared with that in normal tissues.

\section{Discussion}

With the aggravation of environmental pollution, the morbidity and mortality rates of lung cancer have been on the increase, seriously threatening human health (11). At present, the main types of therapy are radiotherapy, chemotherapy and biological immunotherapy. DC is the most powerful APC known currently, playing an important role in triggering the primary immune response in the body for the first time, which can effectively control tumor cell growth and metastasis (12). There are two sources of DC in the body. One is the myeloid-derived DC from bone marrow $\mathrm{CD} 34^{+}$cells, which can stimulate the T-helper cell 1; consequently, it is also known as DC1. Such a cell is the most important source of DC cells at present, which can induce the secretion of a variety of cytokines from $\mathrm{T}$ cells in the body, thus responding to Th1 and finally triggering immune rejection in the body. The other one is lymphocytic DC derived from the thymus, which can stimulate the T-helper cell 2. Consequently, it is also known as DC2. After contacting with the tumor cells in the body, it immediately secretes a variety of cytokines, including interferon- $\alpha$, triggering Th2 immune response, which is closely related to the immune tolerance response in the body $(13,14)$.

In the present study, the number of DCs and its subsets were detected via indirect immunofluorescence and LSCM. The results of the statistical analysis revealed that DC1 and DC2 in lung cancer tissues were significantly increased compared with those in para-carcinoma and normal lung tissues $(\mathrm{P}<0.05)$, and the number of DC1 and DC2 in para-carcinoma tissues was increased compared with that in the normal tissues $(\mathrm{P}<0.05)$. The expression of DC subsets in peripheral blood in NSCLC patients before and after DC immunotherapy were detected using a flow cytometer. The results revealed that the ratio of $\mathrm{DC} 1$ in peripheral blood in the normal control group was significantly higher than that in NSCLC patients $(\mathrm{P}<0.01)$. There were significant differences in $\mathrm{DC} 1$ and $\mathrm{DC} 1 / \mathrm{DC} 2$ ratio in NSCLC patients with different tumor staging, and they also had obvious differences in patients with different KPS scores. Compared with those before treatment, DC1 and DC1/DC2 were significantly increased after three treatments, and there was a significant difference in DC1/DC2 between NSCLC patients with the survival time greater than and less than one year.

It is currently known that DC1 in peripheral blood is reduced in a variety of malignant tumors, such as pancreatic, colorectal and liver cancer (15-17). However, there are also exceptions, such as myeloma (18). Previous findings have shown that the number of DC1 in peripheral blood does not change significantly in myeloma patients. Additionally, the increase of expression levels of various cytokines in serum is closely related to the decrease in DC in peripheral blood (18). The experiment further confirmed that the supernatant of tumor cells cultured in vitro can inhibit the differentiation of DC in vitro, and it is speculated that the tumor cells secrete some cytokines, thus inhibiting the differentiation of DC precursor in vivo (19-21). This may be one of the reasons why the anti-tumor effect of DC therapy in vivo is less than that in vitro.

In conclusion, the immune function of NSCLC patients is improved after DC immunotherapy. The survival time of NSCLC patients is closely related to the DC1/DC2 ratio in peripheral blood. The detection of DC subsets in peripheral blood can help clinicians understand the immune function of NSCLC patients and provide a basis for the clinical judgment of prognosis of NSCLC patients.

\section{Acknowledgements}

The abstract of the present study was published in $\mathrm{J}$ Clin Oncol 35 (Suppl 15): e17574, 2017.

\section{Funding}

No funding was received.

\section{Availability of data and materials}

The datasets used and/or analyzed during the present study are available from the corresponding author on reasonable request.

\section{Authors' contributions}

ZY contributed to analysis using flow cytometry and wrote the manuscript. FD performed LSCM detection. LM performed and analysed detection of the number of DC subsets. All authors read and approved the final manuscript.

\section{Ethics approval and consent to participate}

This study was approved by the Dezhou People's Hospital Ethics Committee (Dezhou, China). All the subjects signed informed consent.

\section{Consent for publication}

Not applicable.

\section{Competing interests}

The authors declare that they have no competing interests. 


\section{References}

1. Teramoto K, Ozaki Y, Hanaoka J, Sawai S, Tezuka N, Fujino S, Daigo Y and Kontani K: Predictive biomarkers and effectiveness of MUC1-targeted dendritic-cell-based vaccine in patients with refractory non-small cell lung cancer. Ther Adv Med Oncol 9: 147-157, 2017.

2. Zhang L, Yang X, Sun Z, Li J, Zhu H, Li J and Pang Y: Dendritic cell vaccine and cytokine-induced killer cell therapy for the treatment of advanced non-small cell lung cancer. Oncol Lett 11: 2605-2610, 2016.

3. Li R, Fang F, Jiang M, Wang C, Ma J, Kang W, Zhang Q, Miao Y, Wang D, Guo Y, et al: STAT3 and NF- $\mathrm{BB}$ are simultaneously suppressed in dendritic cells in lung cancer. Sci Rep 7: 45395, 2017.

4. Mendoza L: Dendritic cell vaccines against non-small cell lung cancer - an emerging therapeutic alternative. Klin Onkol 27: 294-298, 2014

5. Liu X, Li J, Liu Y, Ding J, Tong Z, Liu Y, Zhou Y and Liu Y: Calreticulin acts as an adjuvant to promote dendritic cell maturation and enhances antigen-specific cytotoxic $\mathrm{T}$ lymphocyte responses against non-small cell lung cancer cells. Cell Immunol 300: 46-53, 2016.

6. Zhou C, Liu D, Li J, Sun H, Zheng X, Wang S, Hong G, Mallampati S, Sun H, Zhou X, et al: Chemotherapy plus dendritic cells co-cultured with cytokine-induced killer cells versus chemotherapy alone to treat advanced non-small-cell lung cancer: A meta-analysis. Oncotarget 7: 86500-86510, 2016.

7. Rafei H,El-Bahesh E, Finianos A, Nassereddine S and Tabbara I: Immune-based therapies for non-small cell lung cancer. Anticancer Res 37: 377-387, 2017.

8. Shi SB, Tang XY, Tian J, Chang CX, Li P and Qi JL: Efficacy of erlotinib plus dendritic cells and cytokine-induced killer cells in maintenance therapy of advanced non-small cell lung cancer. J Immunother 37: 250-255, 2014.

9. Zhao M, Li H, Li L and Zhang Y: Effects of a gemcitabine plus platinum regimen combined with a dendritic cell-cytokine induced killer immunotherapy on recurrence and survival rate of non-small cell lung cancer patients. Exp Ther Med 7: 1403-1407, 2014.

10. Takahashi H, Okamoto M, Shimodaira S, Tsujitani S, Nagaya M, Ishidao T, Kishimoto J and Yonemitsu Y; DC-vaccine study group at the Japan Society of Innovative Cell Therapy (J-SICT): Impact of dendritic cell vaccines pulsed with Wilms' tumour-1 peptide antigen on the survival of patients with advanced non-small cell lung cancers. Eur J Cancer 49: 852-859, 2013.

11. Zhong R, Han B and Zhong H: A prospective study of the efficacy of a combination of autologous dendritic cells, cytokine-induced killer cells, and chemotherapy in advanced non-small cell lung cancer patients. Tumour Biol 35: 987-994, 2014.
12. Aguilar-Cazares D, Meneses-Flores M, Prado-Garcia H, Islas- Vazquez L, Rojo-Leon V, Romero-Garcia S, Rivera-Rosales RM and Lopez-Gonzalez JS: Relationship of dendritic cell density, HMGB1 expression, and tumor-infiltrating lymphocytes in non-small cell lung carcinomas. Appl Immunohistochem Mol Morphol 22: 105-113, 2014.

13. Hradilova N, Sadilkova L, Palata O, Mysikova D, Mrazkova H, Lischke R, Spisek R and Adkins I: Generation of dendritic cell-based vaccine using high hydrostatic pressure for non-small cell lung cancer immunotherapy. PLoS One 12: e0171539, 2017.

14. Zhu XP, Xu YH, Zhou J and Pan XF: A clinical study evaluating dendritic and cytokine-induced killer cells combined with concurrent radiochemotherapy for stage IIIB non-small cell lung cancer. Genet Mol Res 14: 10228-10235, 2015.

15. Besse B, Charrier M, Lapierre V, Dansin E, Lantz O, Planchard D, Le Chevalier T, Livartoski A, Barlesi F, Laplanche A, et al: Dendritic cell-derived exosomes as maintenance immunotherapy after first line chemotherapy in NSCLC. Oncoimmunology 5: e1071008, 2015.

16. Han RX, Liu X, Pan P, Jia YJ and Yu JC: Effectiveness and safety of chemotherapy combined with dendritic cells co-cultured with cytokine-induced killer cells in the treatment of advanced non-small-cell lung cancer: A systematic review and meta-analysis. PLoS One 9: e108958, 2014.

17. Yuanying Y, Lizhi N, Feng M, Xiaohua W, Jianying Z, Fei Y, Feng J, Lihua H, Jibing C, Jialiang L, et al: Therapeutic outcomes of combining cryotherapy, chemotherapy and DC-CIK immunotherapy in the treatment of metastatic non-small cell lung cancer. Cryobiology 67: 235-240, 2013.

18. Kovarova L, Buchler T, Pour L, Zahradova L, Ocadlikova D, Svobodnik A, Penka M, Vorlicek J and Hajek R: Dendritic cell counts and their subsets during treatment of multiple myeloma. Neoplasma 54: 297-303, 2007.

19. Ma J, Liu H and Wang X: Effect of ginseng polysaccharides and dendritic cells on the balance of Th1/Th2 T helper cells in patients with non-small cell lung cancer. J Tradit Chin Med 34: 641-645, 2014.

20. Zhang L, Xu Y, Shen J, He F, Zhang D, Chen Z, Duan Y and Sun J: Feasibility study of DCs/CIKs combined with thoracic radiotherapy for patients with locally advanced or metastatic non-small-cell lung cancer. Radiat Oncol 11: 60, 2016.

21. Zhao P, Bu X, Wei X, Sun W, Xie X, Li C, Guo Q, Zhu D, Wei X and Gao D: Dendritic cell immunotherapy combined with cytokine-induced killer cells promotes skewing toward Th2 cytokine profile in patients with metastatic non-small cell lung cancer. Int Immunopharmacol 25: 450-456, 2015.

This work is licensed under a Creative Commons

Attribution-NonCommercial-NoDerivatives 4.0 International (CC BY-NC-ND 4.0) License. 